\title{
Test Study on Mechanical Properties of Mixture Mass of Loess and Crushed Rocks ${ }^{1}$
}

\author{
Sun Wen-jun ${ }^{1}$, Song Yang ${ }^{1 *}$, Guo Ke-xin ${ }^{1}$,Zhang Hai-feng ${ }^{2}$ \\ ${ }^{1}$ Hebei Engineering and Technical College, Cangzhou 061001, Hebei, China; ${ }^{2}$ Hebei University of \\ Technology, Tianjin, 300401, China;
}

Keywords: tunnel; triaxial tests; mixture mass of loess and crushed rocks; double yield surface model

\begin{abstract}
Based on large-scale triaxial tests, the mechanical properties of loess and crushed rocks mixture mass of a freeway tunnel's surrounding rocks in Hebei were studied under the consideration of crushed rock's contents. The test results indicate that with the increase of crushed rocks contents, initial slope of deviatoric stress and axial strain curve increases at the same confining pressure. And corresponding axial strain decreases at the maximum partial stress value. At the same time, the mixture mass shows the characteristics of crisping deformation. Additionally, with the increase of crushed rocks contents, the internal frictional angle increases but the corresponding cohesion decreases. Therefore, the mechanical constitutive relationship of loses and crushed rocks mixture mass was simulated with double yield surface model. The method for determining the model parameters of this model was put forward at the same time.
\end{abstract}

\section{Introduction}

The "coarse phase" (also known as giant grain group or coarse grain group) and "fine particle phase", which constitute the mixture mass of loess and crushed rocks, have significant differences in physical properties and mechanical strength $[1,2]$. The physico-mechanical properties of mixture mass of loess and crushed rocks are different from "fine-grained soil" and "rock" in standard [3, 4, 5]. The definition of mixture mass of loess and crushed rocks put forward by Wenjie Xu et al [6, 7, 8 ] is that formed since the quatemary period, composed of block stone with certain engineering scale and higher strength, but the research on the mixture of loess and gravel is relatively rare [7,8].

\section{Test analysis of tunnel's mixture mass of loess and crushed rocks}

Test sample of mixture mass of loess and rocks and its physical property index. The test sample of mixture mass of loess and crushed rocks was obtained from the left line of a freeway's tunnel in Hebei near the no.K25+240 pile. Its grain size distribution curve is shown in Fig. 1. As seen in Fig. 1 , the content of the particle size which more than $10 \mathrm{~mm}$ is about $15 \%$. In addition, the main physical properties index of the loess are obtained by the conventional soil mechanics test as shown in Table 1.

Firstly, there is $24 \mathrm{~h}$-isotropic consolidation under confining pressure. Then, triaxial shear test with no drainage was carried out under the shearing rate of $0.5 \% / \mathrm{min}$ axial strain. And the test readings are $r$ according to the frequency of $0.5 \%$ axial strain.

\footnotetext{
${ }^{1}$ This paper is supported by the Research Foundation of Education Bureau of He Bei Province (QN2015036);Water resources research and extension project of Hebei Province (2015049)
} 


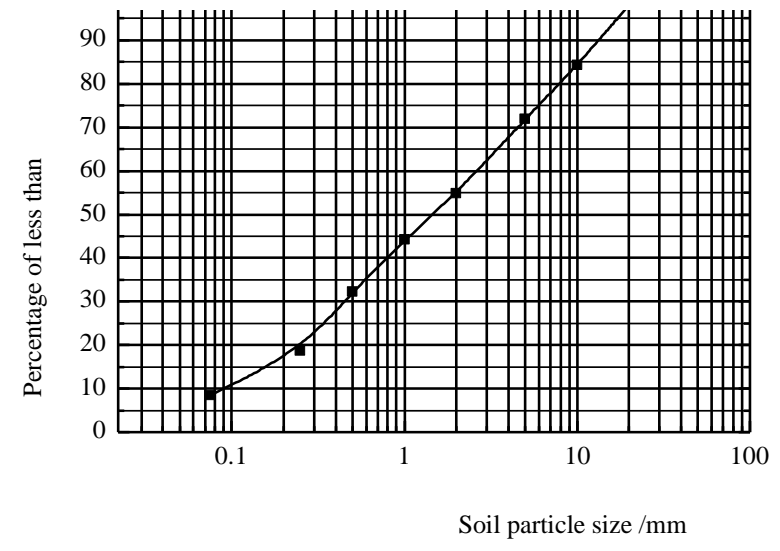

Fig.1 Grain sizes of distribution of mixture

\begin{tabular}{|c|c|c|c|c|}
\hline $\begin{array}{c}\text { Soil } \\
\text { samp } \\
\text { le }\end{array}$ & $\begin{array}{c}\text { Natur } \\
\text { al } \\
\text { unit } \\
\text { weig } \\
\text { ht } \gamma \\
(\mathrm{kN} / \\
\mathrm{m} 3)\end{array}$ & $\begin{array}{c}\text { Dry } \\
\text { unit } \\
\text { weight } \\
\gamma_{\mathrm{d}} \\
(\mathrm{kN} / \mathrm{m} 3 \\
\quad)\end{array}$ & $\begin{array}{c}\text { Natur } \\
\text { al } \\
\text { water } \\
\text { conte } \\
\text { nt } \\
W(\% \\
\quad)\end{array}$ & $\begin{array}{c}\text { Void } \\
\text { ratio } \\
e\end{array}$ \\
\hline $\begin{array}{c}\text { mixt } \\
\text { ure } \\
\text { mass }\end{array}$ & 19.21 & 16.95 & 13.24 & 0.57 \\
\hline
\end{tabular}

Table 1 Physical property parameters

\section{Test results analysis of mixture mass of loess and crushed rocks of tunnels}

As shown in Fig.2 to 4, the relationship curves between axial strain and deviatoric stress as well as volumetric strain are described in triaxial shear tests with different confining pressure of three kinds of gravel content.

Then, the triaxial shear strength characteristic parameters (that is angle of internal friction and cohesion) of tunnel's mixture mass of loess and crushed rocks in different conditions can be obtained by the use of molar circle tangent according to triaxial shear test results with different gravel content, as shown in Table 2. In the process of increase, reduction of soil compaction porosity and distance between gravels, and change of distribution structure are the main change of mixture mass of loess and crushed rocks.

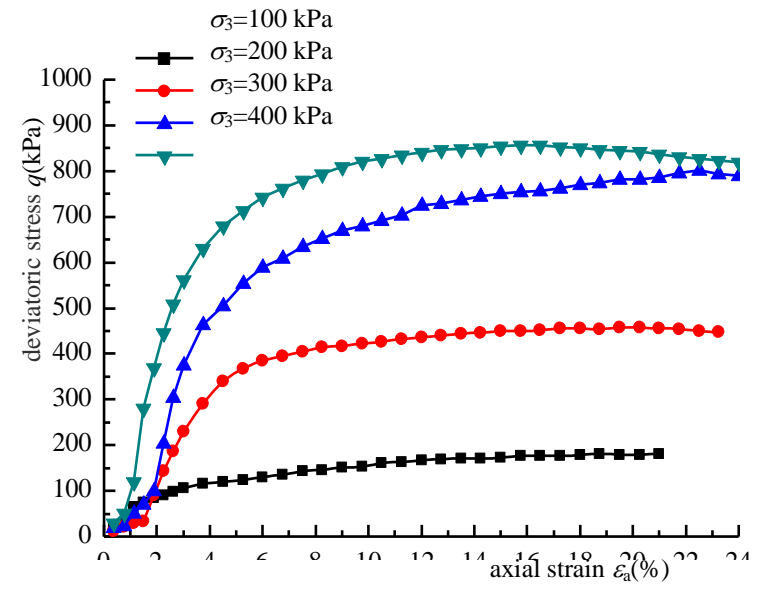

(a) deviatoric stress axial strain

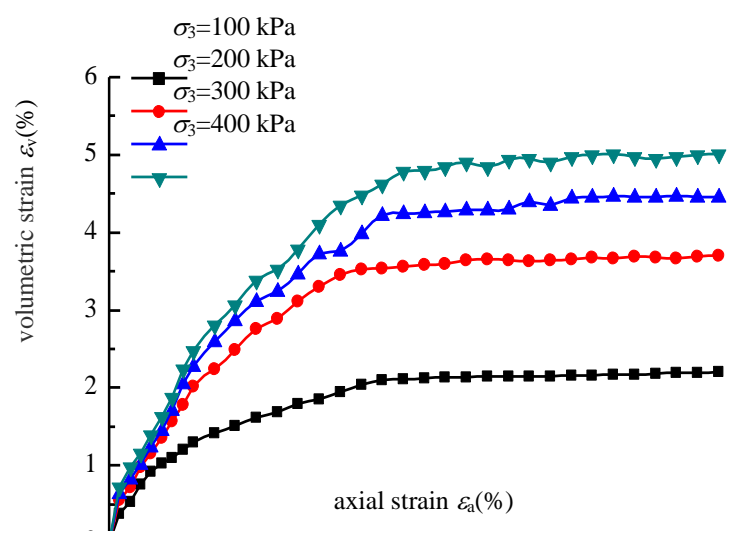

(b) axial strain volume strain

Fig. 2 Triaxial tests results of mixture mass with $10 \%$ crushed rocks 


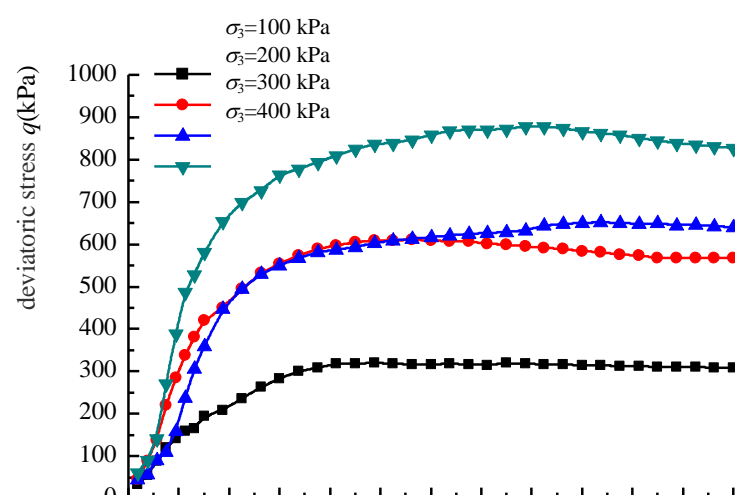

(a) deviatoric stress $\sim$ axial strain

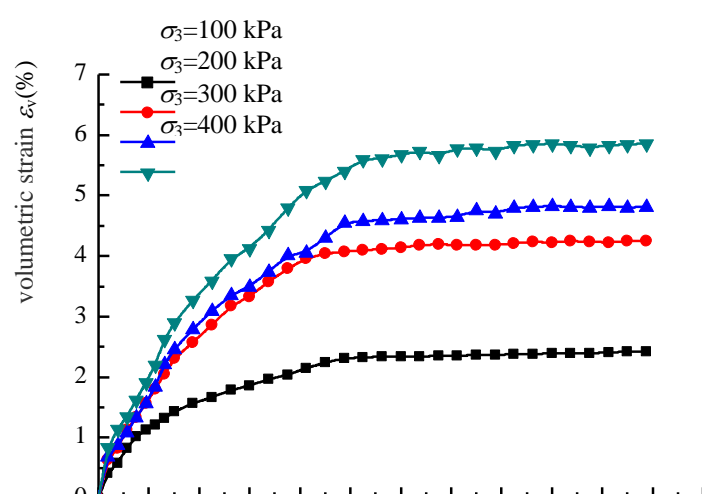

(b) axial strain $\sim$ volume strain

Fig. 3 Triaxial tests results of mixture mass with $20 \%$ crushed rocks

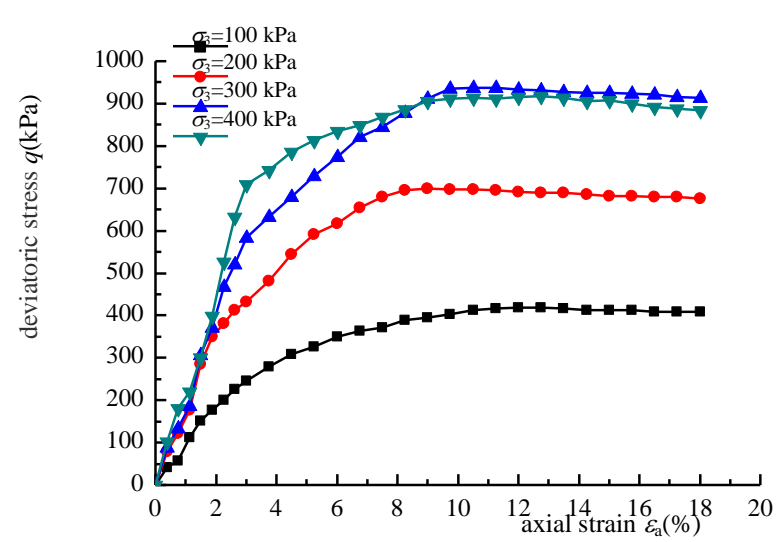

(a) deviatoric stress $\sim$ axial strain

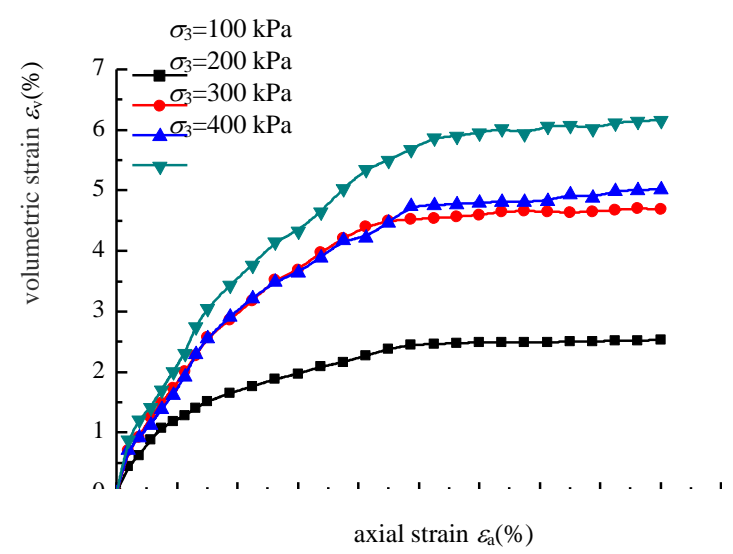

(b) axial strain $\sim$ volume

Fig.4 Triaxial tests results of mixture mass with $30 \%$ crushed rocks

\begin{tabular}{lcccc}
\hline \multirow{2}{*}{\begin{tabular}{l}
\multirow{2}{*}{ indensity } \\
gravel content
\end{tabular}} & \multicolumn{2}{c}{ normal peak intensity } & \multicolumn{2}{c}{ residual intensity } \\
\cline { 2 - 5 } & $\begin{array}{c}\text { internal } \\
\text { friction angle } \\
\phi\left({ }^{\circ}\right)\end{array}$ & $\begin{array}{c}\text { cohesion } \\
\text { force } \\
c(\mathrm{kPa})\end{array}$ & $\begin{array}{c}\text { internal } \\
\text { friction angle }\end{array}$ & $\begin{array}{c}\text { Cohesion } \\
\phi(\mathrm{kPa})\end{array}$ \\
\hline $10 \%$ & 26.89 & 65.34 & 25.14 & 62.64 \\
$20 \%$ & 27.67 & 61.12 & 26.43 & 53.21 \\
$30 \%$ & 28.84 & 51.90 & 28.24 & 51.40 \\
\hline
\end{tabular}

Table 2 Index of shear strength for mixture mass

\section{Research on constitutive model of the mixture mass of loess and crushed rocks}

At present, the constitutive model of mixture mass of loess and crushed rocks mainly bases on the constant elasticity modulus and Poisson's ratio. Currently, after the soil mass reaches its yield, the description of yield surface mainly contains shear yield surface and volume collapse yield surface. And double yield surface which combined by two of them is commonly used. The hardening parameter of the yield surface is plastic volume strain $\varepsilon_{v}^{p}$ and the shear stain $\varepsilon_{s}^{p}$, taking the plastic shear stain and plastic shear stain into consideration. In this paper, the model of mixture mass of loess and crushed rocks is simulated by the double yield surface model. 


\section{Shear yield surface of mixture mass of loess and crushed rocks.}
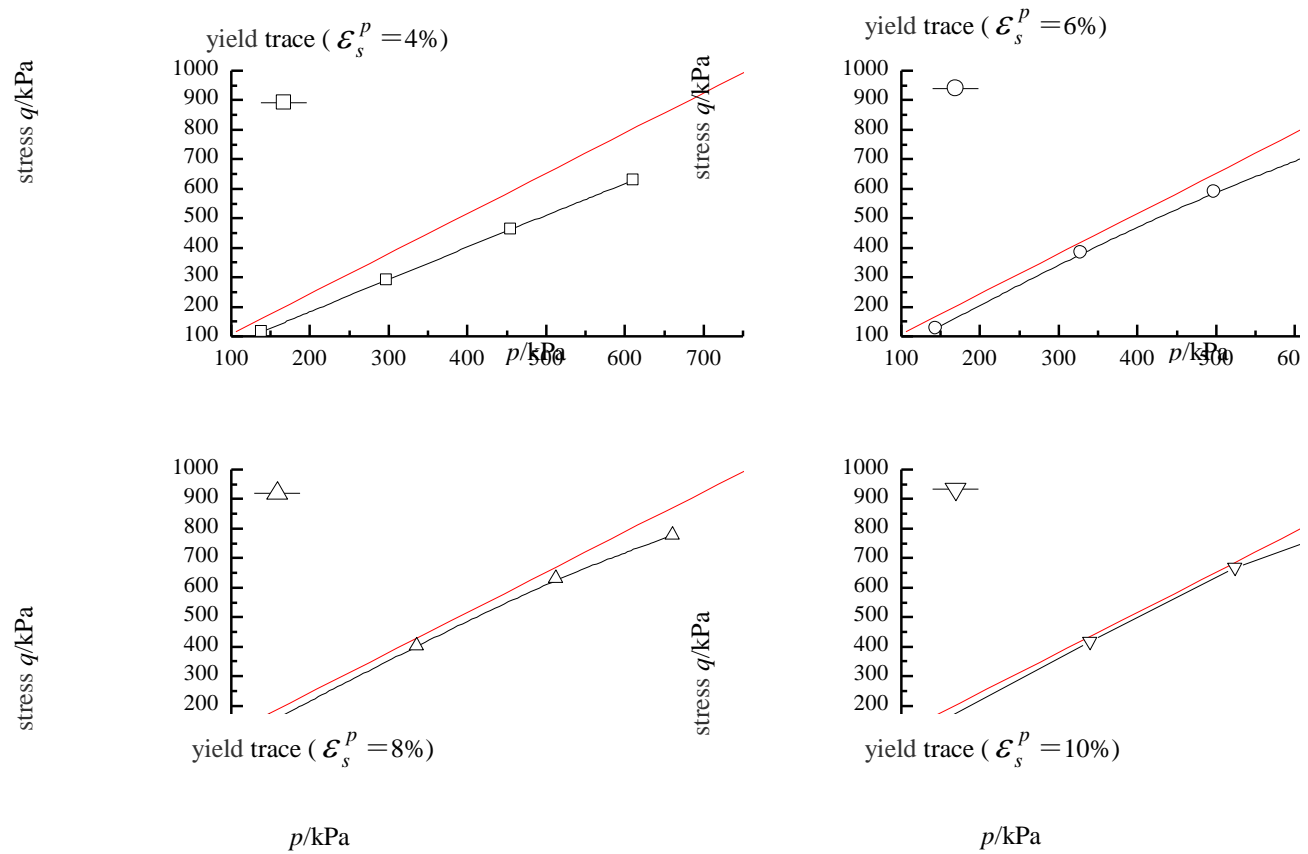

Fig. 5 Trace of plastic strain change for mixture mass with $10 \%$ crushed rocks

And then the fitting results of the corresponding stress yield trace by hyperbolic function with plastic shear strain of mixture mass of loess and crushed rocks is $4 \%, 6 \%, 8 \%$ and $10 \%$ under different gravel contents in Table 3.

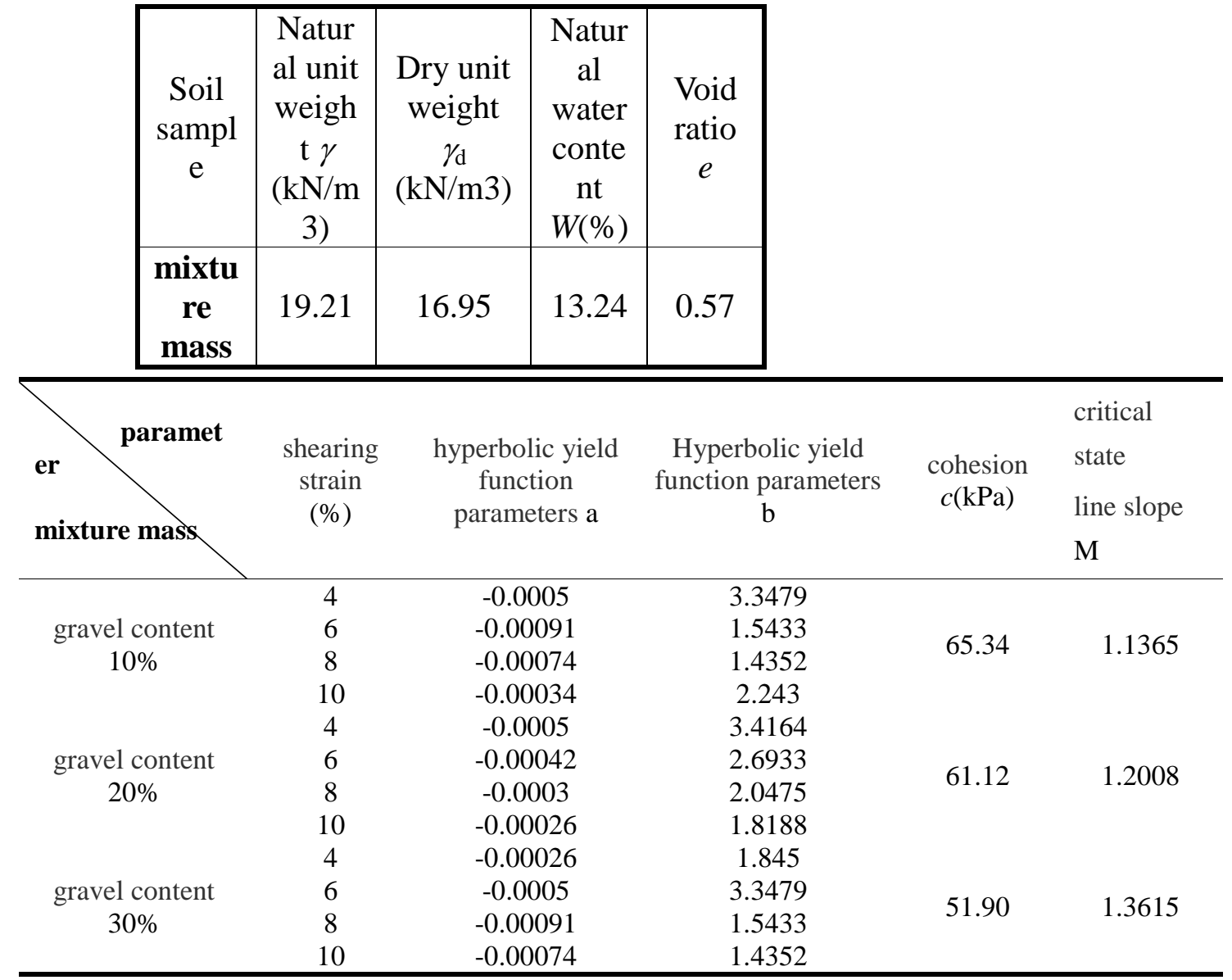

Table 3 The shear yield surface parameters for mixture mass considering different contents of crushed rocks 


\section{Conclusion}

An indoor large triaxial tests carried out for the mechanical properties of mixture mass of loess and crushed rocks of a freeway's tunnel in Hebei. The impact of gravel on loess mass was analyzed by changing its content. And then, the stress and strain characteristics of mixture mass of loess and crushed rocks were simulated by using double yield surface model. And main conclusions of this paper are as followed:(1) The deviatoric stress increases obviously with the increase of gravel content under the same confining pressure, especially when the gravel content increases to $30 \%$. (2) Mixture mass of loess and crushed rocks has brittle characteristics when the gravel content gradually increases from $10 \%$ to $20 \%$ and $30 \%$. And when gravel content increases to $30 \%$, the internal friction angle of mixture mass of loess and crushed rocks increases by $7.3 \%$, while the cohesion decreases by $20.6 \%$. (3) Put forward the double yield model to simulate the mixture mass of loess and crushed rocks and determine the model parameters.

\section{References}

[1] Chen Xiaobin, Zhang Jiasheng, Zhao Tongshun, Test study on the red sandstone granular soil's double yiled elastoplastic constitutive model, Journal of Plasticity Engineering. 14 (2007) 123- 129. [2] Xu Wenjie, Hu Ruilin, Zeng Ruyi, Research on horizontal push-shear in-situ test of subwater soil-rock mixture, Chinese Journal of Geotechnical Engineering. 28 (2006) 814-818.

[3] Luo Gang, Zhang Jianmin, Improvement of Duncan-Chang nonlinear model and Shen Zhujiang's elastoplastic model for granular soils, Rock and Soil Mechanics. 25 (2004) 887-890.

[4] He Changrong, Yang Guifang, Effects of parameters of Duncan-Chang model on calculated results, Chinese Jounal of Geotechnical Engineering. 24 (2002) 345-450.

[5] Shu Zhile, Liu Xinrong, Liu Xianbao, Li Yue, Granule fractal properties of earth-rock aggregate and relationship between its gravel content and strength, Journal of Central South University (Science and Technology). 41 (2011) 1123-1126.

[6] Xu Wenjie, Hu Ruilin, Yue Zhongqi, Tan Rujiao, Mesostructural character and numerical simulation of mechanical properties of soil-rock mixtures, Chinese Journal of Rock Mechanics and Engineering. 26 (2007) 300-310.

[7] You Xinhua, Stochastic structural model of the earth-rock aggregate and its application, Chinese Journal of Rock Mechanics and Engineering. 21 (2002) 1748-1752. 